\title{
An Empirical Study of Logistics Strategy for Service Quality at Retail Malls at Thane City and Suburban Mumbai in India
}

\author{
Parvathi Venkatesh \\ Principal, Mulund College of Commerce, \\ Dr. Sarojini Naidu Road, Mulund, 40080, Mumbai, India \\ Email: parvathi.v@ rediffmail.com
}

\begin{abstract}
The present study is a survey approach to measure service quality with reference to current thinking of consumers and their future requirements. It is an analysis of evaluating the gap between customer perceptions and expectations of service quality in selected agglomerated retail shopping centres in Thane and eastern suburbs of Mumbai in India. Data were collected from 600 customers of large retail shopping stores using structured questionnaire. Basic framework of SERVQUAL model has been adapted and seven customer quality dimensions were introduced to suit the purpose. The scores have been further analysed by using Inferential Statistical Test. The study showed distinctive results for the relationship between service quality dimensions and service quality. The result shows that at group level, all logistic dimensions of service quality such as Access, Architecture, Assortment and Alignment positively influences the service quality as the customer perceived service are high to their expectations. The result also indicates that gap in specific attributes in the subgroups like safety and security arrangements are statistically significant.This paper serves a model mapping for retail managers and provides valuable information that may help them to better understand the customers' preferences and the business.
\end{abstract}

Keywords: agglomerated retail stores, service quality dimensions, SERVQUAL model, gap analysis, perception and expectation.

\section{INTRODUCTION}

Logistics are used in almost every industry, as a core strategy to gain customer loyalty. Logistic competency is to do everything precisely right at the first time to improve retention rate as well as competitive abilities. In case of agglomerated stores in cities, the resources are committed to achieve high levels of store specific basic service competency that competitors cannot duplicate. These service specialists adopt promotion focused value added service initiatives which involve unique point of sales display modules aimed at stimulating sales. Many promotion focused value added services include logistical support of point - of - sale advertising and promotional materials. Multiple products from varied suppliers are mixed and displayed in a multi-tiered display units specially designed to fit a specific retail store. This 'catch me if you can' approach to logistic operations results in orchestrating product availability and operational performance along with perfect support activities such as invoice accuracy and appropriate product presentation with zero defects.

\section{RATIONALE OF THE STUDY}

Customer service management has been a subject of great interest to organizations and researchers alike. The quality of service has become an important aspect of customer retention. Realizing the significance of customercentered philosophies, agglomerated stores in cities have begun to invest heavily on solutions that optimize interactions from the customer's perspective that will enhance customer loyalty. To get customers loyalty, retailers must create relationships with the customers. To create relationship with customers, retailers need to conduct research on how the customers make their purchasing decision and whether they are pleased with what the organization provides to them as offer in terms of location of centres, product quality, service quality, price, the ergonomics etc. In the light of the above, the current study is made to analyze the logistic strategy of large agglomerated stores towards service quality by considering customers' perceptions and expectations of services from these retail centers.

\section{STATEMENT OF RESEARCH PROBLEM}

Research has always been concentrated in measuring service quality or SERVQUAL for customer services. This marketing research study tries to relate promotion focused value added services in large retail outlets as a logistic strategy to assess service quality. It uses the standard SERVQUAL framework to identify the gap between customers' service expectations to and their perceptions towards service quality. What most researchers have a consensus on is that SERVQUAL is a crucial element in Customer Satisfaction even when the offering involved a combination of products and services. The current study aims at measuring the influences of logistic strategy and service quality in Retailing. Every marketing effort is directed to be customer focused and hence it is imperative that retailing strategy or promotional initiatives result in higher customer retention levels.

\section{OBJECTIVES OF THE STUDY}

The main purpose of this study theoretically is finding out how applicable the SERVQUAL model is in the context 
of grocery stores and empirically, describe how consumers perceive service quality and whether they are satisfied with the services offered by these stores in Indian cities. The primary objectives of this study include exploring the emergence, role and development of logistic strategy in product service systems in the fast spreading concept of agglomerative retail stores in Indian metro cities, assessing promotion focused service initiatives by analyzing the service gap at these stores, examining the existing as well as future requirement of service infrastructure and the promotion and marketing agglomerated stores as an important retailing system in Indian Scenario. The specific objectives of the study can be grouped as under:

- To Evaluate service quality in selected agglomerated retail stores in eastern Mumbai suburbs and Thane city in India;

- To identify the role of logistics and promotion focused service initiatives to improve service quality;

- To explore user expectations and to assess perception level towards service quality in 15 agglomerated stores in Thane and Mumbai eastern suburbs;

- To ascertain whether any actual or perceived gaps exist between customer expectations and perceptions of the service offered in retail stores or not;

- To point out how management of service improvement can become more logical and integrated with respect to the prioritized service quality dimensions and their effect on increasing/decreasing service quality gaps;

- To develop the best market solutions which leverage delivery of superior quality of service result in higher customer satisfaction levels.

\section{METHODOLOGY}

This paper starts with understanding the concept of Logistic competency and its role in enhancing service quality and demonstrates the model of service quality gaps. For the fulfillment of the basic objectives, data for the study were collected through field survey. The research design of this paper is an experimental study on the basis of primary data collected from various centers in and around area stretching between Thane city and Mumbai eastern suburbs. This study evaluates the customer perceptions of service quality in selected large retail stores as compared to customer expectations. It is intended to identify the effectiveness of the logistics in promotion focused services at the stores by exploring the difference in experiences and expectations of the customer.

The study follows the SERVQUAL as a framework and dimensions of analysis were modified to suit the purpose of the study. Standard statistical tool of average was used for comparison and to underline service gaps. In addition, null hypothesis significance testing was performed by using Paired $\mathrm{t}$ test to test the hypotheses and for analyzing the statistical significance of data separately and in a group.

\section{Hypotheses:}

1) Logistic competency and Service quality is a crucial element in retailing and significantly impact on customer satisfaction and value perceptions.

2) There is a significant gap between Customers' service expectations and their perceptions of service quality offered in agglomerated retail stores.

3) Influence of Service quality in retailing is measurable through gap between customers' expectations and customers' perceptions.

4) Customer experience is fundamentally different from customer service.

\section{SERVQUAL model and GAP analysis:}

Service quality is a concept that has aroused considerable interest and debate in the research literature because of the difficulties in both defining it and measuring it with no overall consensus emerging on either (Wisniewski, 2001). Nowadays, with the increased competition, service quality has become a popular area of academic investigation and has been recognized as a key factor in keeping competitive advantage and sustaining satisfying relationships with customers.(Zeithmal et al.,2000).Service quality can be defined as the difference between customer's expectations for service performance prior to the service encounter and their perceptions of the service received. (Asubonteng et al.1996). Service quality can be the difference between customer expectations of service and perceived service. If expectations are greater than performance, then perceived quality is less than satisfactory and hence customer dissatisfaction occurs (Parasuraman et al., 1985; Lewis and Mitchell, 1990). Rise of consumerism in urban centers during globalised era necessitates promotion based service initiatives to ascertain market presence of leading retailers.

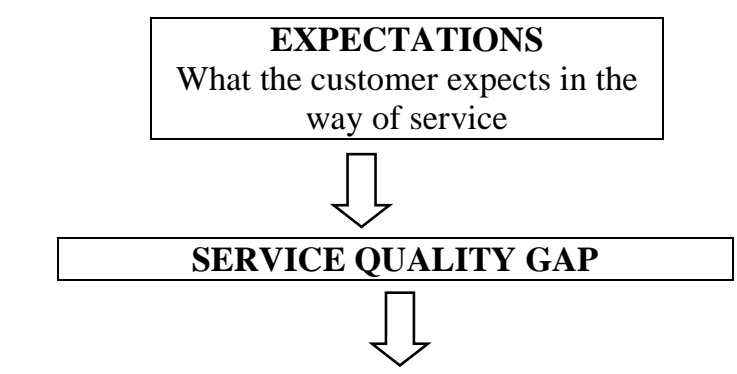

\section{PERCEPTIONS}

What the customer thinks they got in the way of service

Figure 1 the Service Quality Gap

Service quality occurs when expectations are met. With the help of survey method, an average (mean) gap score between perception and expectation of customers can be arithmetically calculated. If E represents the expectations score and $\mathrm{P}$ represents the perceptions score, the gap score, $\mathrm{G}$, is:

$$
G=P-E
$$

That is, the gap score is the perceptions score minus the expectation score or the difference between present level 
of service quality obtained by the consumers and the needed level by them. A negative gap score implies that customer expectations are not being met. Clearly, the larger the gaps score the larger the gulf between what the customers expected from the retailer and what they felt they actually received. With a 5-point scoring scale, the gap score could vary from -4 to +4 with zero implying expectation was met exactly. In marketing studies, it is assumed that such gap scores are likely to be negative for most services - public and private sector alike. Varied reasons could be associated while analysing feasibility of meeting the expectations. It may be too expensive to allocate required resources to meet anticipations, some expectations may not be realistically achievable, and expectations may have risen over time. However, information on levels of customer expectations can help managers understand what customers actually expect of a particular service. Similarly, information on service quality gaps can help managers to identify where performance improvement can best be targeted. Equally, if gap scores in some areas do turn out to be positive, this allows managers to review whether they may be 'oversupplying' this particular feature of the service and whether there is potential for re-deployment of resources into features which are under performing.

\section{SAMPLING DESIGN}

Data were collected by using a non-probability sampling technique based on Convenience and quantitative data was obtained from 600 customers of 25 retail-shopping stores. Respondents were those who had visited the sample stores at least two times earlier and first time visitors to the stores were not included. The study administered a structured and modified SERVQUAL questionnaire containing two sections: customers' expectations and customers' perceptions each consisting of 30 questions of seven dimensions.

\section{DATA ANALYSIS AND FINDINGS}

Table 1 SERVQUAL Mean scores for retailing in agglomerated retail stores at Thane and Mumbai eastern suburbs

\begin{tabular}{|l|c|c|c|}
\hline \multicolumn{1}{|c|}{ Dimensions } & $\begin{array}{c}\text { Perceptions } \\
\text { (present } \\
\text { level) }\end{array}$ & $\begin{array}{c}\text { Expectations } \\
\text { (needed } \\
\text { level) }\end{array}$ & $\begin{array}{c}\text { Gap } \\
\text { scores } \\
\text { (P-E) }\end{array}$ \\
\hline Access & 3.49 & 3.36 & 0.13 \\
\hline Architecture & 3.61 & 3.39 & 0.22 \\
\hline Assortment & 3.48 & 3.39 & 0.09 \\
\hline Assistance & 3.44 & 3.22 & 0.22 \\
\hline Alignment & 3.53 & 3.35 & 0.18 \\
\hline Augmentation & 3.51 & 3.24 & 0.27 \\
\hline Association value & 3.52 & 3.37 & 0.15 \\
\hline $\begin{array}{l}\text { Overall Mean } \\
\text { score }\end{array}$ & 3.51 & 3.33 & 0.18 \\
\hline
\end{tabular}

Service quality is assessed through seven service quality dimensions. The study is rooted from seven different dimensions of Customer Experience in relation to promotion focused value added service initiatives namely Access, Architecture, Assortment, Assistance, Alignment, Augmentation and Association value and customers' viewpoints are obtained on each of these attributes to have a better understanding of the core theme. The respondents were asked to rate their expectations and perceptions about unique point of sales display service offered by the respective retail stores and a five point Likert scale was used. After Data cleaning, the $\mathrm{N}$ turned out to be 475 .

Service quality occurs when expectations are met and at the outset, an analysis of Table 1 reveals that the present level of customers' perception about service quality offered in the sample retail stores exceeds the expectations of the customers and a positive gap score implies that there is a higher level of perceived quality. All means are between values 3 and 4 i.e. between good and very good scales in the Likert which echoes that consumers are largely satisfied with the logistics strategy of these retail stores. However, an insight into the subgroup of each of these dimensions unfolds interesting results.

i) In case of the first dimension i.e. 'Access', the gap between perception and expectation of the consumers about the attributes on a) location of stores with indicators to reach them, b) approach and supporting infrastructure to reach them, and c) parking facilities have minor differences with perception exceeding expectations marginally (gap score $<0.12$ with standard deviation $<1$ ). One single factor showing a wider gap between the mean score has been 'safety and security arrangements' with perception is more than experience to the extent of 0.33 (with S.D. 1.077) giving a clue to the retail managers that customers' expectations are met with, hence there is no need for deployment of additional resources on these lines and resources on this area to some extent can be redistributed on other aspects.

ii) The second logistic dimension 'Architecture' depicts a picture that perceptions (present level) exceed expectations (needed level) with reference to all indicators in the sub group. In addition to a positive gap of 0.22 overall, the scores of all sub attributes (ergonomics, interiors and other aesthetics, aroma experience general upkeep and other hygienic factors at the shops) are also uniformly closer to a positive gap of 0.2 with S.D. around 1; this underlines that customers are largely satisfied with the physical logistic arrangements in the retail outlets.

iii) The third dimension 'Assortment' shows that the expectations are almost fully met with the gap score being 0.09. But within the group, attributes like product categories with display label on individual product has the gap nearer to zero (mean score 0.02 with S.D. 1.09), the same in case of other sub questions like the quality of products sold (gap score $0.11 \&$ S.D.1.02) is lesser than attributes like price Anchoring and cleanliness of product shelves which have a gap of 0.2 (S.D.0.9). The expectations surpass perception with reference to the product varieties depth and the width (e.g. nutrition drink Horlicks has a product variety in synchrony with various price points) offered at the store showing the gap a 
negative score of -0.06 with S.D.1.04.This gives a hopeful hint to the retail managers to focus attention on this area to meet the expectation.

iv) The dimension 4, 'Assistance' contains details on manpower relations describing the gap as being dispersed between sub attributes with regard to (i) number of assistants (ii) responsiveness and (iii) behaviour of them - showing a gap close to 0.3 ; data on gap regarding (iv) product knowledge and (v) willingness to assist is wider (0.24) compared to gap in attributes like communication skills, consistency of performance of stores assistance across all retail stores visits which have been same and closer to nil (0.07) and the representativeness of the samples are also dependable as S.D.=1.

v) The fifth, sixth and seventh dimensions concentrate on customer loyalty and advocacy. The analysis of fifth dimension 'Alignment' with an overall gap score of 0.18 states that 'the coordination between the store manager and the sales assistant' and 'the way brand image, brand appeal \& the store experience are aligned' shows a gap of more than 0.23 but response to query on 'overall impression on the way everything arranged within the store' is having minimal gap score of 0.07 only.

vi) Similarly with reference to the sixth dimension of 'Augmentation' the customers are categorical in their response to gap analysis while revealing that regarding 'the way the store assistants remember my preferences every other time I visit' there is a glaring gap of 0.48 .

vii) The last dimension on 'Association value' draws more attention as all attributes have a negative sign of gap though the value is trifling. The gap to concentrate upon in this dimension is about 'the overall shopping experience at the retail outlet' which reads as perception as 3.51 and expectation as 3.33 effecting a positive gap of 0.34 whereas the reaction to questions on 'encouragement and incentives to share shopping experience' illustrate gap as almost nil. Hence, it can at ease be deduced that while customers have high association value with these retail outlets, they expect much more positively from these large retail stores. An analysis of coefficient of variation suggests that all attributes have C.V. less than $35 \%$ with only exception i.e. overall shopping experience of consumers at the outlet which reads as $45.57 \%$ (Summery statistics enclosed as Annexure 1) manner:

Thus, the hypotheses made are proved in the following

H1: It is true that Logistic competency and Service quality is a crucial element in retailing and they significantly impact on customer satisfaction and value perceptions; the same is reflected in all seven dimensions of this study.

H2: Customer experience is fundamentally different from customer service; Service is measured by seven different dimensions and the experiences are measured by perceptions and expectations and with the help of experiences the quality of customer service is measured.

H3: Influence of Service quality in retailing is measurable through gap between customers' expectations and customers' perceptions; the gap has been measured with the help of survey method, and a definite outcome has been obtained.

H4: There is a significant gap between Customers' service expectations and their perceptions of service quality offered in agglomerated retail stores; the intuitive understanding about existence of a gap is disproved. In majority of service dimensions, the perceptions either meet the expectations or there is a narrow, positive gap (with perceptions marginally above expectations).

\section{Testing of Hypothesis:}

Though the gap analysis exposes interesting results on gap scores, statistical inferential test was preferred to be conducted to analyse the representativeness of the study, To suit the study, paired t test was conducted with a purpose to test whether or not the population mean represented by our sample has some specified value .

The paired t test is generally derived from study subjects who have been measured at two time points (so each individual has two measurements). $95 \%$ confidence interval is derived from the difference between the two sets of paired observations. The paired t-test assumes that analysed data is from a normal distribution. A paired t-test tests a null hypothesis about two means; most often, it tests the hypothesis that two means are equal, or that the difference between them is zero. The t-test allows us to say either "we can reject the null hypothesis of equal means at the 0.05 level" or "we have insufficient evidence to reject the null of equal means at the 0.05 level that is the P-value was compared with a 0.05 level of significance." H0: Null Hypothesis of this study is that the customers' perceptions exactly meet the expectations of the customers and

H1: The corresponding Alternative Hypothesis to be proved / disproved would be that there is a significant gap between Customers' service expectations and their perceptions of service quality offered in agglomerated retail stores.

A paired samples $t$ test was conducted with regard to the data collected from 475 customers in 25 agglomerated stores in order to evaluate the impact of shopping expectations on the perceptions of the consumers with their effect size.

From the sub parameters chosen for measuring customer perceptions and expectations, it is observed that $\mathrm{p}$ value is $(0.000)<0.05$ in relation to three dimensions viz... Architecture, Alignment (except one sub attribute) and Augmentation, therefore the corresponding $t$-value is significant at 0.05 (level of significance) and at df (degree of freedom) 474. Hence in these dimensions null hypothesis is to be rejected. Also that Perception level is more than Expectations. So it is clear that service quality is met in these service dimensions.

However, with reference to service dimensions of Access (except safety measures), Assortment (except Price anchoring and cleanliness) and Association value, $\mathrm{p}$-value is 
above 0.05 and hence the results are statistically not significant and more investigations may be required in these angles.

Further, t-value showing negative signs in case of two major sub attributes viz... i) Depth and the width of Product varieties offered at the store and ii) sharing of shopping experience, and hence retail managers have to concentrate on enhancing these two aspects. The analysis is further extended for calculating the effect size and in all dimensions (including all sub attributes) the eta squared statistic $\mathrm{D}^{2}(<$ 0.06 for paired t-test) indicated a small effect size (Cohen, 1988)

\section{RECOMMENDATIONS \& CONCLUSIONS}

An analysis of the findings of this study can provide a baseline measurement, which will allow retail leadership to benchmark performance of any future retail stores improvements. The findings imply that service quality is not the only factor that could lead to customer satisfaction in large retail centre; that service quality dimension varies in the different retail sectors. The findings suggest that to provide quality service in order to satisfy customers, organizations in this kind of retail sectors need to improve on the dimensions of service quality. This implies that retailers should focus on identifying sector specific service quality dimensions to address their key audience and close the gap between perceptions and expectations to deliver superior quality of services for retaining existing customers as well as to attract new customers. This study may help retailers to identify and prioritise the focal areas of improvement and indicate how to develop and upgrade customer service quality.

This research on measuring service quality has focused primarily on identifying the focal areas to meet or exceed the customers' expectations, and has viewed service quality as a measure of how the delivered service level matches consumers' expectations. This paper serves a model mapping for retailers which may help to better understand the customers' preferences and the business. It will help to strengthen customer relationships and see how all the customer service dimensions affect the bottom line so that the retailers can ultimately improve it. It is envisaged that by using these techniques the existing and new retail stores will enhance Customer Life Time Value by improving Customer Experience Management. The demonstrated methodologies can be further extended by using tools like chi-square test or multiple regression models by incorporating appropriate questions. This research can be extensive and expensive, or it can be integrated into a firm's everyday interactions with customers. The study is expected to provide a careful metric to create a customer experience that really initiates customer loyalty and advocacy which requires thought, effort and a systematic process. The executives will understand what it means to manage the customer experience and then to use a systematic process for doing so in their organizations. The further extension of this report can provide authoritative logistic intelligence for retailing.

Further, towards future research, an important marketing design that can be developed to evaluate how well firms perform on the seven service quality dimensions is the zone of tolerance, which refers to the area between customers' expectations regarding their desired service and the minimum level of acceptable service. That is, the difference between what the customer really wants and what the customer will accept before going elsewhere. To define the zone of tolerance, a researcher has to seek answers to a series of supplementary questions about each service quality dimension that relates to:

- Customers' perceptions of how well the focal service performs and how well a competitive service performs, from low to high.

- The importance of each service quality dimension

- Any other service dimensions unexpressed for which closing of gaps is essential to improve performance of agglomerated retail stores.

To conclude, SERVQUAL by itself, useful though it may be to a service manager, will not give a complete picture of expectations and perceptions in a service organization context. Provision of quality services is a complex zone involving priority listing of meeting not only the identified service dimensions but also unexpressed dimensions, allocation of resources, accountability and justification of the actions initiated etc. Service organizations are responsible and accountable to citizens and communities as well as to customers and service users. There are wider service organization agendas than simply service quality: improving access to existing services; equity and equality of service provision; providing efficient and effective services within existing political environment and resource constraints. The definition of service quality therefore takes on a wider meaning and accordingly its measurement becomes both more complex and more difficult.

\section{REFERENCES}

Aaker, D. A., \& Jones, J. M. (1971). Modelling Store Choice Behaviour, Journal of Marketing Research 8(1), pp. 38-42.

Asubonteng, P., McCleary, K.J. and Swan, J.E. (1996), SERVQUAL revisited: a critical review of service quality, Journal of Services Marketing, 10(6), pp. 6281.

Gupta, U. (2012). Customer Loyalty towards Kiranas in Competitive Environment: A Case study. International Journal of Marketing and Technology, 2(8), pp. 249268.

Karthikeyan G.and.Mayilvaganan S. (2011), Service Gap Analysis - A Study with reference to Public Sector Banks, International Journal of Multidisciplinary Management Studies, 1(3), pp. 234 - 241.

Lewis, B.R. and Mitchell, V.W. (1990), Defining and measuring the quality of customer service, Marketing Intelligence \& Planning, 8(6), pp. 11-17.

McCain, S. L. C., Jang, S. S., \& Hu, C. (2005). Service quality gap analysis toward customer loyalty: practical guidelines for casino hotels. International Journal of Hospitality Management, 24(3), pp. 465-472.

Magesh R. (2010). A study on quality of service as a tool for enhancement of customer satisfaction in banks. Global Journal of Finance and Management, 2(1), pp.123-133. 
Parasuraman, A., Zeithaml, V.A. and Berry, L.L. (1985), A conceptual model of service quality and its implication, Journal of Marketing, 49, pp. 41-50

Talreja M. and Jain D., (2013), Changing Consumer Perceptions Towards Organized Retailing from Unorganized Retailing - An Empirical Analysis, International Journal of Marketing, Financial Services \& Management Research, 2(6), pp. 73-85.

Wisniewski, M. (2001), Using SERVQUAL to assess customer satisfaction with public sector services, Managing Service Quality, 11(6), pp. 380-388.
Wisniewski, M. and Donnelly, M. (1996), Measuring service quality in the public sector: the potential for SERVQUAL, Total Quality Management, 7(4), pp. 357-365.

Zeithaml, V.A., Parasuraman, A. and Berry, L.L. (1990), Delivering quality service; Balancing customer perceptions and expectations, The Free Press, New York, NY

Dr. (Mrs.) Parvathi Venkatesh has 28 years of rich experience in Under Graduate and Post graduate teaching and research in the subject of Business Economics. She is the Principal of Mulund College of Commerce, one of the premier affiliated institutions of University of Mumbai, India. Formerly as the Dean of Faculty of Arts, she has richly contributed towards the introduction of a number of innovative curricula and reforms in evaluation system in the University of Mumbai. She is an assessor of NAAC, the National Accreditation Agency in India and has held various responsibility of every aspect of a college life. 

ANNEXURE I- Summary Statistics

\begin{tabular}{|c|c|c|c|c|c|c|c|c|c|c|c|c|}
\hline \multirow{2}{*}{ Dimensions } & \multicolumn{4}{|c|}{ Expectation } & \multicolumn{4}{|c|}{ Perception } & \multirow{2}{*}{ Gap } & \multirow{2}{*}{ paired $t$} & \multirow{2}{*}{ p } & \multirow{2}{*}{$n^{2}$} \\
\hline & Mean & S.E. & S.D. & C.V & Mean & S.E. & S.D. & C.V & & & & \\
\hline \multicolumn{13}{|l|}{ I) ACCESS } \\
\hline Location of the store is & 3.61 & 0.045 & 0.979 & 27.12 & 3.67 & 0.04 & 0.882 & 24.03 & 0.06 & 1.014 & 0.311 & 0.002 \\
\hline The approach \& supporting infrastructure to reach main store & 3.38 & 0.044 & 0.951 & 28.14 & 3.49 & 0.045 & 0.973 & 27.88 & 0.11 & 1.807 & 0.071 & 0.007 \\
\hline Car/Scooter parking facilities are & 3.37 & 0.046 & 0.995 & 29.53 & 3.42 & 0.047 & 1.014 & 29.65 & 0.05 & 0.758 & 0.449 & 0.001 \\
\hline Location map for store location at ground floor of store is & 3.2 & 0.051 & 1.118 & 34.94 & 3.32 & 0.053 & 1.161 & 34.97 & 0.12 & 1.939 & 0.053 & 0.008 \\
\hline Safety \& security arrangements at mall/store are & 3.24 & 0.054 & 1.18 & 36.42 & 3.57 & 0.049 & 1.077 & 30.17 & 0.33 & 4.463 & 0.000 & 0.040 \\
\hline Total & 3.36 & & & & 3.49 & & & & 0.13 & & & \\
\hline \multicolumn{13}{|l|}{ II) ARCHITECTURE } \\
\hline Ergonomics (physical appearance of goods) of store layout is & 3.49 & 0.049 & 1.076 & 30.83 & 3.71 & 0.045 & 0.988 & 26.63 & 0.22 & 3.509 & 0.000 & 0.025 \\
\hline $\begin{array}{l}\text { The interiors \& the other aesthetics (including lighting, wall hangings/ wall } \\
\text { finishing, floorings etc) are }\end{array}$ & 3.39 & 0.046 & 1.009 & 29.76 & 3.67 & 0.044 & 0.95 & 25.89 & 0.28 & 4.694 & 0.000 & 0.045 \\
\hline Aroma experience at the store is & 3.42 & 0.049 & 1.068 & 31.23 & 3.59 & 0.047 & 1.034 & 28.80 & 0.17 & 2.673 & 0.008 & 0.015 \\
\hline The general upkeep of the store environs(cleanliness) is & 3.35 & 0.051 & 1.12 & 33.43 & 3.51 & 0.046 & 1.012 & 28.83 & 0.16 & 2.641 & 0.009 & 0.015 \\
\hline $\begin{array}{l}\text { Other hygiene factors encouraging my shopping time } \& \text { adding on to pleasant } \\
\text { experience at store-like air conditioning, music, child play area, trial rooms, } \\
\text { billing encounters etc are }\end{array}$ & 3.33 & 0.051 & 1.103 & 33.12 & 3.55 & 0.046 & 0.993 & 27.97 & 0.22 & 3.517 & 0.000 & 0.025 \\
\hline Total & 3.39 & & & & 3.61 & & & & 0.22 & & & \\
\hline \multicolumn{13}{|l|}{ III) ASSORTMENT } \\
\hline The prices of the products sold in the outlet (Price Anchoring) & 3.44 & 0.049 & 1.074 & 31.22 & 3.65 & 0.043 & 0.927 & 25.40 & 0.21 & 3.923 & 0.000 & 0.031 \\
\hline The quality of products sold in the outlet & 3.47 & 0.048 & 1.056 & 30.43 & 3.58 & 0.047 & 1.023 & 28.58 & 0.11 & 1.743 & 0.082 & 0.006 \\
\hline $\begin{array}{l}\text { Product category (toilet soaps / kits, t-shirts etc) and individual product display } \\
\text { labels within stores are }\end{array}$ & 3.38 & 0.044 & 0.964 & 28.52 & 3.4 & 0.05 & 1.093 & 32.15 & 0.02 & 0.447 & 0.655 & 0.000 \\
\hline The product varieties depth and the width offered at the store is & 3.44 & 0.052 & 1.046 & 30.41 & 3.38 & 0.051 & 1.04 & 30.77 & $\underline{-0.06}$ & -0.997 & 0.319 & 0.002 \\
\hline The cleanliness across the product category shelves is & 3.22 & 0.052 & 1.144 & 35.53 & 3.41 & 0.05 & 1.099 & 32.23 & 0.19 & 3.162 & 0.002 & 0.021 \\
\hline Total & 3.39 & & & & 3.48 & & & & 0.09 & & & \\
\hline
\end{tabular}


Venkatesh: Empirical Study of Logistic Strategy for Service Quality at Retail Malls at Thane City and Suburban Mumbai in India

\section{ANNEXURE I- Summary Statistics (Con't}

\begin{tabular}{|c|c|c|c|c|c|c|c|c|c|c|c|c|}
\hline \multirow{2}{*}{ Dimensions } & \multicolumn{4}{|c|}{ Expectation } & \multicolumn{4}{|c|}{ Perception } & \multirow{2}{*}{ Gap } & \multirow{2}{*}{ paired $t$} & \multirow{2}{*}{$p$} & \multirow{2}{*}{$n^{2}$} \\
\hline & Mean & S.E. & S.D. & C.V & Mean & S.E. & S.D. & C.V & & & & \\
\hline \multicolumn{13}{|l|}{ IV) ASSISTANCE } \\
\hline product knowledge of sales assistant is & 3.34 & 0.051 & 1.116 & 33.41 & 3.57 & 0.049 & 1.076 & 30.14 & 0.23 & 3.162 & 0.002 & 0.021 \\
\hline Communication skills of the sales assistant is & 3.22 & 0.051 & 1.105 & 34.32 & 3.29 & 0.049 & 1.079 & 32.80 & -0.07 & 0.976 & 0.330 & 0.002 \\
\hline The willingness of the sales assistants to assist is & 3.15 & 0.051 & 1.119 & 35.52 & 3.39 & 0.046 & 1.006 & 29.68 & 0.24 & 3.351 & 0.001 & 0.023 \\
\hline Responsiveness of the sales assistant is & 3.18 & 0.049 & 1.075 & 33.81 & 3.48 & 0.046 & 1.01 & 29.02 & 0.30 & 4.449 & 0.000 & 0.040 \\
\hline The behavior of the sales assistant is & 3.09 & 0.051 & 1.108 & 35.86 & 3.44 & 0.046 & 0.997 & 28.98 & 0.35 & 5.358 & 0.000 & 0.057 \\
\hline The number of sales assistant to assist is & 3.28 & 0.047 & 1.03 & 31.40 & 3.57 & 0.047 & 1.025 & 28.71 & 0.29 & 4.833 & 0.000 & 0.047 \\
\hline $\begin{array}{l}\text { The consistency of the sales assistants performance across all my store visits } \\
\text { is }\end{array}$ & 3.27 & 0.049 & 1.061 & 32.45 & 3.34 & 0.05 & 1.096 & 32.81 & 0.07 & 1.013 & 0.312 & 0.002 \\
\hline Total & 3.22 & & & & 3.44 & & & & 0.22 & & & \\
\hline \multicolumn{13}{|l|}{ V) ALIGNMENT } \\
\hline $\begin{array}{l}\text { The way everything within the store ( upkeep of store, product display, sales } \\
\text { assistants' behaviors, prices and quality of product sold etc) are aligned is }\end{array}$ & 3.56 & 0.05 & 1.095 & 30.76 & 3.63 & 0.044 & 0.969 & 26.69 & 0.07 & 1.022 & 0.307 & 0.002 \\
\hline The coordination between the store manager and the sales assistant is & 3.27 & 0.048 & 1.036 & 31.68 & 3.51 & 0.047 & 1.026 & 29.23 & 0.24 & 3.831 & 0.000 & 0.030 \\
\hline The way brand image, brand appeal $\&$ the store experience are aligned is & 3.23 & 0.052 & 1.137 & 35.20 & 3.46 & 0.048 & 1.056 & 30.52 & 0.23 & 3.696 & 0.000 & 0.028 \\
\hline Total & 3.35 & & & & 3.53 & & & & 0.18 & & & \\
\hline \multicolumn{13}{|l|}{ VI) AUGMENTATION } \\
\hline The way I am treated every other time that I visit the store is & 3.43 & 0.047 & 1.014 & 29.56 & 3.62 & 0.043 & 0.935 & 25.83 & 0.19 & 3.26 & 0.001 & 0.022 \\
\hline $\begin{array}{l}\text { The way the store assistants remember my preferences every other time I visit } \\
\text { is }\end{array}$ & 2.99 & 0.05 & 1.083 & 36.22 & 3.47 & 0.051 & 1.121 & 32.31 & 0.48 & 6.391 & 0 & 0.079 \\
\hline $\begin{array}{l}\text { The frequency and the way I'm informed of all the new product launches, new } \\
\text { product promotion schemes etc is }\end{array}$ & 3.29 & 0.047 & 1.033 & 31.40 & 3.45 & 0.05 & 1.081 & 31.33 & 0.16 & 2.609 & 0.009 & 0.014 \\
\hline Total & 3.24 & & & & 3.51 & & & & 0.27 & & & \\
\hline \multicolumn{13}{|l|}{ VII) ASSOCIATION VALUE } \\
\hline The way I'm encouraged to share my shopping experience at this mall is & 3.46 & 0.051 & 1.104 & 31.91 & 3.45 & 0.05 & 1.098 & 31.83 & $\underline{-0.01}$ & -0.153 & 0.878 & 0 \\
\hline
\end{tabular}

\section{ANNEXURE I- Summary Statistics (Con't)}


Venkatesh: Empirical Study of Logistic Strategy for Service Quality at Retail Malls at Thane City and Suburban Mumbai in India Operations and Supply Chain Management 8(3) pp. 128-136 @ 2015

\begin{tabular}{|c|c|c|c|c|c|c|c|c|c|c|c|c|}
\hline \multirow{2}{*}{ Dimensions } & \multicolumn{4}{|c|}{ Expectation } & \multicolumn{4}{|c|}{ Perception } & \multirow{2}{*}{ Gap } & \multirow{2}{*}{ paired $t$} & \multirow{2}{*}{$\mathbf{p}$} & \multirow{2}{*}{$\mathrm{n}^{2}$} \\
\hline & Mean & S.E. & S.D. & C.V & Mean & S.E. & S.D. & C.V & & & & \\
\hline \multicolumn{13}{|l|}{ VII) ASSOCIATION VALUE } \\
\hline The incentive for me to share my shopping experience at store is & 3.33 & 0.044 & 0.966 & 29.01 & 3.43 & 0.048 & 1.037 & 30.23 & 0.10 & 1.866 & 0.063 & 0.007 \\
\hline The overall shopping experience at this mall/outlet is & 3.33 & 0.044 & 0.966 & 29.01 & 3.67 & 0.077 & 1.671 & 45.53 & 0.34 & 0.811 & 0.418 & 0.001 \\
\hline Total & 3.37 & & & & 3.52 & & & & 0.15 & & & \\
\hline Overall Mean Score & 3.33 & & & & 3.51 & & & & 0.18 & & & \\
\hline
\end{tabular}

